\title{
ENTRE O PRINCÍPIO DA INTERVENÇÃO MÍNIMA E A EXPANSÃO PENAL: A (IN)EFETIVIDADE DA PROTEÇÃO PENAL À PROPRIEDADE INDUSTRIAL
}

\author{
Nigel Stewart Neves Patriota Malta ${ }^{1}$ \\ Márcio Roberto Torres ${ }^{2}$
}

\section{RESUMO}

Este trabalho busca demonstrar que a proteção penal, por força do princípio da intervenção mínima, é tida como ultima ratio, criminalizando condutas em prol da preservação dos bens jurídicos mais importantes de uma sociedade, salvaguardando, inclusive, a propriedade industrial (marcas, patentes, indicações geográficas e concorrência desleal). Buscou-se estudar as circunstâncias referentes a sua (in)efetividade. Não obstante os delitos previstos na Lei no 9.279/1996 (arts. 183 a 195), este ensaio objetiva reflexionar sobre os efeitos pedagógicos da proteção penal à propriedade industrial. A pesquisa foi efetivada, quanto à abordagem, de forma qualitativa, por revisão bibliográfica, com a utilização do método descritivo.

Palavras-chave: Direito da Propriedade Intelectual; Marcas e patentes; Crimes; Intervenção mínima; Efeitos pedagógicos.

\section{BETWEEN THE PRINCIPLE OF MINIMUM INTERVENTION AND CRIMINAL EXPANSION: THE (IN)EFFECTIVENESS OF CRIMINAL PROTECTION TO INDUSTRIAL PROPERTY}

\begin{abstract}
This work seeks to demonstrate that criminal protection, by virtue of the principle of minimum intervention, is considered as ultima ratio, criminalizing conduct for the preservation of the most important legal assets of a society, safeguarding even industrial property (trademarks, patents, geographical indications and unfair competition). It was sought to study the circumstances regarding its (not)effectiveness. Notwithstanding the offenses set forth in Law $\mathrm{n}^{\circ}$ 9.279/1996, this essay aims to reflect on the pedagogical effects of criminal protection on industrial property. The research was carried out, regarding the approach, in a qualitative way, by bibliographic review, using the descriptive method.
\end{abstract}

\footnotetext{
${ }^{1}$ Mestrando em Direito Público pela Universidade Federal de Alagoas - UFAL. Pós-graduado em Formação para a Docência do Ensino Superior (CESMAC). Foi Diretor-Geral do Tribunal de Justiça do Estado de Alagoas, onde atua como Chefe de Gabinete.

${ }_{2}^{2}$ Mestrando em Direito Público pela Universidade Federal de Alagoas - UFAL. Pós-graduado em Direito Processual (CESMAC). Advogado. Professor Universitário. Procurador-Geral Adjunto do Município de Maceió/AL.
} 
Keywords: Intellectual Property Law; Trademarks and patents; Crimes; Minimum intervention; Pedagogical effects.

\section{INTRODUÇÃO}

A propriedade industrial no Brasil é regida pela Lei n 9.279/1996 - Lei da Propriedade Industrial (LPI). Seu intuito é disciplinar as relações jurídicas originadas das criações intelectuais, sobretudo aquelas de caráter industrial, como as marcas e patentes. Difere do direito autoral, porquanto este diz respeito às criações regulamentadas pela Lei nº 9.610/1998 - Lei dos Direitos Autorais (LDA).

As criações industriais podem ser classificadas como invenções, modelos de utilidade, marcas e desenhos industriais, tendo o amparo da legislação específica nos âmbitos cível e criminal (COELHO, 2011, p. 107). Isso demonstra a relevância jurídica da propriedade industrial para o mundo contemporâneo, especialmente no tocante aos efeitos econômicos erigidos das tendências mercadológicas sobre as marcas e patentes (MALLMANN, 2016).

Com efeito, o Direito Penal, por força do princípio da intervenção mínima, é tido como ultima ratio, criminalizando condutas em prol da preservação dos bens jurídicos mais importantes de uma sociedade (PRADO, 2010, p. 69). Dessa forma, o presente trabalho se propõe a estudar circunstâncias referentes à (in)efetividade da proteção criminal à propriedade industrial.

Não obstante os delitos previstos na $\mathrm{LPI}^{3}$, buscou-se, a partir das discussões oriundas da relação entre intervenção mínima e expansão penal criminalizadora, refletir sobre os efeitos pedagógicos da proteção penal à propriedade industrial, a partir de uma visão crítica do assunto tratado, tendo em vista a importância da temática, especialmente para o contexto da sociedade globalizada.

\footnotetext{
${ }^{3}$ Os delitos estão previstos na LPI dos arts. 183 a 195, distribuídos no Título V (Dos crimes contra a propriedade industrial), que conta com sete capítulos (Capítulo I - Dos crimes contra as patentes; Capítulo II - Dos crimes contra os desenhos industriais; Capítulo III - Dos crimes contra as marcas; Capítulo IV - Dos crimes cometidos por meio de marca, título de estabelecimento e sinal de propaganda; Capítulo V - Dos crimes contra indicações geográficas e demais indicações; Capítulo VI - Dos crimes de concorrência desleal), além de um Capítulo que versa sobre as disposições gerais (Capítulo VII) (BRASIL, 1996).
} 
Desse modo, visando à abordagem de todo o conteúdo de forma harmônica e dinâmica, tratar-se-á dos crimes contra a propriedade industrial e seus aspectos procedimentais, seguido do estudo sobre a intervenção mínima e a expansão criminalizadora. A partir daí, serão analisados os aspectos relativos à (in)efetividade da proteção penal à propriedade intelectual e a necessidade dos efeitos pedagógicos.

Por meio de revisão bibliográfica, com a utilização do método descritivo, o presente estudo se propõe a reunir os mais diversos referenciais teóricos acerca da matéria, sendo a pesquisa efetivada, quanto à abordagem, de forma qualitativa.

\section{OS CRIMES CONTRA A PROPRIEDADE INDUSTRIAL}

Por propriedade industrial entende-se, de forma simplificada, aquela que se tem sobre determinado bem econômico não material, sendo este passivo de apropriação por terceiros quando colocado no mercado. A propriedade industrial é espécie do gênero propriedade intelectual (RAMOS, 2010, p. 187).

O Direito deve incidir sobre tais situações na medida em que elas se tornam frequentes na sociedade, acarretando demandas diversas a partir das relações sociais. Nesse percurso, foi necessária a criação de proteções jurídico-normativas que resguardassem o direito de propriedade sobre os bens intelectuais, entre os quais estão inseridos os de propriedade industrial, buscando não só salvaguardar os valores econômicos oriundos da criação ao seu proprietário, como também incentivar o fomento de pesquisas e produções intelectuais que favoreçam, em diversos aspectos, a evolução da sociedade (RAMOS, 2010, p. 188-191).

A partir disso constata-se a relevância da proteção penal aos bens jurídicos disciplinados pela propriedade industrial, sobretudo diante das imbricações dessa proteção nos âmbitos da livre iniciativa e da livre concorrência, bem como em virtude de seus reflexos para a economia de um país.

“A proteção da Propriedade Industrial permite também a disseminação do conhecimento tecnológico, uma vez que as invenções são tornadas públicas, possibilitando sua utilização por terceiros após a expiração da proteção" (COSTA, 2005). A Constituição Federal (CF) de 1988, em seu art. 5º, inciso XXIX, dispõe sobre 
a propriedade industrial, assim como sobre sua temporalidade, visando às contribuições e fins sociais (BRASIL, 1988).

Para tratar especificamente da propriedade industrial, o legislador criou a Lei 9.279/96, conhecida como LPI, que regula os direitos e obrigações relativos à propriedade industrial. Em seu art. $2^{\circ}$, incisos I a III, quatro espécies de bens imaterias foram protegidas: $i$ ) a patente de invenção; ii) patente de modelo de utilidade; iii) o desenho industrial; $i v$ ) a marca (BRASIL, 1996; COELHO, 2011, p. 107). Além disso, a LPI reprime "as falsas indicações geográficas e a concorrência desleal" (RAMOS, 2010, p. 191).

A propriedade sobre o bem econômico e imaterial é solicitada por meio do Instituto Nacional de Propriedade Industrial (INPI). Somente após a concessão pelo referido órgão é possível a exploração econômica exclusiva sobre o bem, estando, portanto, assegurada a sua propriedade industrial (COSTA, 2005; COELHO, 2011, p. 107).

Assim como contra os bens materiais, os bens imateriais de propriedade industrial também estão sujeitos a crimes que devem ser observados à luz do Direito. Os crimes contra o patrimônio imaterial estão "relacionados com os crimes de sonegação fiscal, corrupção, contrabando, descaminho, lavagem de dinheiro, evasão de divisas, entre outros", pois suprimem impostos, geram prejuízos ao consumidor e afetam "a oferta de empregos na economia formal" (FILIZZOLA, 2005, p. 89).

O Título V da LPI trata dos crimes contra a propriedade industrial, sobre os quais serão tecidas algumas considerações. O referido título é constituído de sete capítulos. Com exceção do último (Capítulo VII), que se refere às disposições gerais, os seis primeiros versam sobre condutas delituosas, agrupadas de acordo com suas principais características (BRASIL, 1996).

No artigo inicial do referido título, tem-se que as condutas consistentes na fabricação de produto objeto de patente ou modelo de utilidade, bem assim na utilização de meio ou processo objeto de patente de invenção, ambas sem a necessária autorização do titular, constituem crime, previsto no art. 183, incisos I e II, cuja pena, de detenção, é prevista abstratamente no patamar de 3 (três) meses a 1 (um) ano, ou multa (BRASIL, 1996). 
A fabricação do produto, mencionada no referido dispositivo legal incriminador, não diz respeito apenas a seu resultado final e integral, mas atinge também a qualquer parte, assim como aos processos utilizados para a fabricação, pois ligados à essência ou à fundamentalidade do produto, a saber, os meios empregados para a materialização do produto.

O modo mais comum de violação à patente é a reprodução fidedigna, ou melhor, idêntica, da invenção, com todas as suas características e especificidades. Por outro lado, não obstante o agente praticante "simular" a falsificação do produto, atribuindolhe modificações e alterações à substância original, isso não elide o crime, uma vez que há transgressão de aspectos da criação contidos na patente (PIERANGELI, 2003). Assim, existirá a simulação mesmo que a imitação não seja autêntica ou perfeita, desde que haja a reprodução de pontos essenciais do objeto patenteado (OLIVEIRA, 2011).

A esse respeito, Oliveira (2011) menciona que, por "meio ou processo" deve-se entender a forma de produção específica de um produto, como, por exemplo, a fabricação de embalagens "tetrapak".

Segundo Pierangeli (2003), para que de fato o crime se concretize, é imprescindível que o produto seja uma cópia perfeita, capaz de induzir ao erro àqueles sem habilidades e perícia na área, ou seja, a pessoa comum (homem médio).

No art. 184, o legislador dispõe como crime contra patente de invenção ou de modelo de utilidade a exportação, venda, exposição ou oferta à venda, manutenção em estoque, ocultação ou ainda o recebimento, para utilização com fins econômicos, de produto fabricado com violação de patente de invenção ou modelo de utilidade, além daquele obtido por meio ou processo patenteado (BRASIL, 1996).

Também incide no mesmo crime aquele que pratica a importação de produto que seja objeto de patente de invenção ou modelo de utilidade, bem assim o obtido por meio ou processo patenteado no país, para os fins previstos no inciso I do referido artigo, e que não tenha sido colocado no mercado externo diretamente pelo titular da patente ou com seu consentimento (BRASIL, 1996).

Para esse delito, a pena, de detenção, é ainda menor que a prevista no artigo anterior, variando de 1 (um) a 3 (três) meses, ou multa. Vale ressaltar que neste caso não precisa o agente obter vantagens econômicas com a prática de sua ação, bastando 
incorrer em qualquer uma das práticas descritas nos incisos I e II do art. 184 (BRASIL, 1996).

No art. 185, aparece como crime de propriedade industrial o fornecimento de componente de um produto patenteado, material ou equipamento para a realização de um processo patenteado, desde que a aplicação final do componente, material ou equipamento induza, necessariamente, à exploração do objeto da patente. Para este crime a pena, de detenção, é de 1 (um) a 3 (três) meses, ou multa.

Sobre o disposto no art. 185, Oliveira (2011) leciona que, no caso, busca-se reprimir os "crimes acessórios" à falsificação ou à reprodução de produto ou modelo de utilidade. Dessa forma, punem-se inclusive os atos preparatórios da falsificação, ao incriminar a conduta de ministrar os equipamentos e materiais essenciais à produção do bem falsificado (PIERANGELI, 2003).

"Como o bem juridicamente tutelado é o direito assegurado pela patente, de se concluir que todos os meios que possam impedir ou ameaçar a sua intangibilidade, ou seja, por em xeque a sua integridade mediante a contrafação, devem ser reprimidos" (PIERANGELI, 2003, p. 200).

Como regra geral, especificada pelo legislador, os crimes do Capítulo I caracterizam-se ainda que a violação não atinja todas as reivindicações da patente ou se restrinja à utilização de meios equivalentes ao objeto da patente, conforme previsão estatuída no art. 186 da LPI (BRASIL, 1996).

No que concerne ao Capítulo II, têm-se os crimes contra o desenho industrial. Primeiramente, faz-se necessário mencionar que se considera desenho industrial a forma plástica ornamental de um objeto ou o conjunto ornamental de linhas e cores que possa ser aplicado a um produto, proporcionando resultado visual novo e original na sua configuração externa e que possa servir de tipo de fabricação industrial, cujo registro é um título de propriedade temporária sobre um desenho industrial, outorgado pelo Estado aos autores ou outras pessoas físicas ou jurídicas detentoras dos direitos sobre a criação (PLETSCH, 2009).

Destarte, o art. 187 da LPI tem em seu texto que a fabricação, sem autorização do titular, de produto que incorpore desenho industrial registrado, ou imitação substancial que possa induzir em erro ou confusão, incorre em crime, cuja pena, de 
detenção, acha-se abstratamente prevista entre 3 (três) meses e 1 (um) ano, ou multa (BRASIL, 1996).

Já o art. 188 explicita que constitui crime contra registro de desenho industrial a exportação, venda, exposição ou oferta à venda, manutenção em estoque, ocultação ou recebimento, para utilização com fins econômicos, de objeto que incorpore ilicitamente desenho industrial registrado, ou imitação substancial que possa induzir em erro ou confusão; como também a importação de produto que incorpore desenho industrial registrado no país, ou imitação substancial que possa induzir em erro ou confusão, para os fins previstos no inciso I do art. 188 da LPI, e que não tenha sido colocado no mercado externo diretamente pelo titular ou com seu consentimento, cominando a pena, de detenção, prevista abstratamente entre 1 (um) e 3 (três) meses, ou multa (BRASIL, 1996).

Tais redações guardam semelhança com os dispositivos que se referem à patente industrial, ou seja, ambos, patente e desenho industrial, mantêm uma similaridade nos crimes que ocorrem a partir de suas propriedades industriais.

Ao tratar sobre a marca, a LPI, em seus arts. 189 e 190, dispõe como crime contra o registro de marca a reprodução, sem autorização do titular, no todo ou em parte, de marca registrada, assim como também quem a imita, de forma que possa induzir confusão; do mesmo modo, ocorre com a alteração de marca registrada de outrem já aposta em produto colocado no mercado (BRASIL, 1996).

Também comete crime contra registro de marca quem importa, exporta, vende, oferece ou expõe à venda, oculta ou tem em estoque produto assinalado com marca ilicitamente reproduzida ou imitada, de outrem, no todo ou em parte; ou produto de sua indústria ou comércio, contido em vasilhame, recipiente ou embalagem que contenha marca legítima de outrem (BRASIL, 1996).

Para o previsto no artigo 189, a pena, de detenção, é de 3 (três) meses a 1 (um) ano, ou multa; para o art. 190, a pena, de detenção, é de 1 (um) a 3 (três) meses, ou multa (BRASIL, 1996).

Assim, de acordo com Hannickel (2013), o que deve ser coibido é a reprodução da parte essencial, primordial, da marca que fora anteriormente registrada. Ainda que se acrescente ou se retire algo da composição da marca, caso sejam mantidos elementos ou 
partes significativas que sejam idênticas à da marca anteriormente registrada, isso também resulta em empecilho ao novo registro e, portanto, configura crime contra registro de marca.

$\mathrm{O}$ art. 191 prevê como delito a reprodução ou imitação, de modo que possa induzir em erro ou confusão, de armas, brasões ou distintivos oficiais nacionais, estrangeiros ou internacionais, sem a necessária autorização, no todo ou em parte, em marca, título de estabelecimento, nome comercial, insígnia ou sinal de propaganda, ou o uso dessas reproduções ou imitações com fins econômicos, sob pena de detenção, de 1 (um) a 3 (três) meses, ou multa. Ainda, incorre na mesma pena quem vende, expõe ou oferece à venda os produtos assinalados com essas marcas (BRASIL, 1996).

A esse respeito, importante assinalar a ementa do julgamento da apelação criminal n. 1996.61.81.003681-0, pela Quinta Turma do Tribunal Regional Federal da $3^{\text {a Região: }}$

PENAL. VIOLAÇÃO DO ART. 191 DA LEI $\mathrm{N}^{\circ}$ 9.279/96. MATERIALIDADE E AUTORIA DELITIVAS COMPROVADAS. NÃO CONFIGURADA A EXCLUDENTE DE ILICITUDE OU CULPABILIDADE. BASTA A SIMPLES IMITAÇÃO PARA CONFIGURAR O DELITO. APELAÇÃO DESPROVIDA. Apelação contra sentença por meio da qual o acusado foi condenado a 180 diasmulta como incurso no art. 191 da Lei $n^{\circ}$ 9.279/96. Segundo a denúncia, o acusado era presidente e diretor de entidades e vinha se utilizando de símbolo que imita o Brasão da República como timbre de seus documentos, de modo a induzir as pessoas em erro ou confusão. [...] Não há que se falar em exclusão da ilicitude ou da culpabilidade. Basta a simples imitação, a falsa aparência, para que haja a consumação do crime. Restou provado que o apelante utilizavase de maneira dolosa da imitação de símbolo oficial para revestir suas organizações com a imagem de órgãos públicos com o intuito de captar clientes. Os documentos nos quais autoridades políticas deramlhe as congratulações pela sua iniciativa não autorizam a utilização de símbolo similar a oficial pelas instituições por ele criadas (art. 124, inc. I, da Lei $n^{\circ}$ 9.279/96). [...] Apelação desprovida. (TRF-3 - ACR: 3681-SP - 1999.61.81.003681-0, Relator: Desembargador Federal Andre Nabarrete, Data de Julgamento: 12/04/2004, Quinta Turma).

Outros delitos previstos na LPI, contidos nos arts. 192 a 194, dizem respeito à proteção das indicações geográficas e demais indicações. Segundo o texto legal, consiste em crime, com previsão de pena, de detenção, cominada, em abstrato, de 1 (um) a 3 (três) meses, ou multa, a fabricação, importação, exportação, venda, exposição 
ou oferecimento à venda ou manutenção em estoque de produto que apresente falsa indicação geográfica (BRASIL, 1996).

De igual modo, consiste em crime a utilização, em produto, de recipiente, invólucro, cinta, rótulo, fatura, circular, cartaz ou em outro meio de divulgação ou propaganda, de termos retificativos, tais como "tipo", "espécie", "gênero", "sistema", "semelhante", "sucedâneo", "idêntico", ou equivalente, não ressalvando a verdadeira procedência do produto. Para essas ações a pena prevista é de detenção, de 1 (um) a 3 (três) meses, ou multa (BRASIL, 1996).

Por sua vez, o art. 194 define como crime a utilização de marca, nome comercial, título de estabelecimento, assim como insígnia, expressão ou sinal de propaganda ou qualquer outra forma que indique procedência que não a verdadeira. Incorre no mesmo delito quem praticar a venda ou exposição à venda de produto com esses sinais, sendo a pena prevista em abstrato, de detenção, de 1 (um) a 3 (três) meses, ou multa (BRASIL, 1996).

É preciso primeiramente compreender que as indicações geográficas adquirem a natureza de um bem, que agrega valor ao fundo de negócio de todos aqueles que exploram a atividade em determinada região, influenciando a economia local e sendo por isso objeto de interesse coletivo de todos os integrantes daquela comunidade. (FRAGA, 2013; RODRIGUES; MENEZES, 2000).

Fraga (2013) faz referência para exemplificar as indicações geográficas ao "Vale dos Vinhedos", tida como a primeira reconhecida pelo INPI, requerida pela Associação dos Produtores de Vinho do Vale dos Vinhedos (APROVALE). Concedida em 2002, seus produtos identificados são os vinhos produzidos na região do referido vale. É sobre este tipo de indicação que incorrem as ações mencionadas nos arts. 192 a 194 da LPI (BRASIL, 1996).

Por fim, na lista dos crimes contra a propriedade industrial estão aqueles relacionados à concorrência desleal, descritos a partir dos incisos do artigo 195 da LPI. ${ }^{4}$

\footnotetext{
${ }^{4}$ Art. 195. Comete crime de concorrência desleal quem: I - publica, por qualquer meio, falsa afirmação, em detrimento de concorrente, com o fim de obter vantagem; II - presta ou divulga, acerca de concorrente, falsa informação, com o fim de obter vantagem; III - emprega meio fraudulento, para desviar, em proveito próprio ou alheio, clientela de outrem; IV - usa expressão ou sinal de propaganda alheios, ou os imita, de modo a criar confusão entre os produtos ou estabelecimentos; V - usa, indevidamente, nome comercial, título de estabelecimento ou insígnia alheios ou vende, expõe ou oferece à venda ou tem em estoque produto com essas referências; VI - substitui, pelo seu próprio nome ou razão
} 
A livre concorrência acirra a competição entre empresários que lutam bravamente pelos mesmos consumidores. Assim, a disputa pela clientela e pela ampliação de mercado é constante no sistema capitalista e constitui, não apenas para os empresários, mas para os consumidores, um ótimo fator, já que estes encontram à disposição, no mercado, inúmeras opções de escolha entre serviços e/ou bens de boa qualidade e preços adequados.

A livre concorrência está também prevista no art. 171 da CF de 1988, onde fica claro que a ordem econômica, fundada na valorização do trabalho humano e na livre iniciativa, tem por objetivo assegurar a todos existência digna, conforme os ditames da justiça social, observados alguns princípios, entre os quais se insere a livre concorrência e a defesa do consumidor (BRASIL, 1988).

Assim sendo, os crimes contra a propriedade industrial, para além de sua relação aos diretamente ofendidos, pretendem resguardar toda a sociedade, e em particular o público consumidor, principal responsável pela movimentação da economia nacional.

\section{INTERVENÇÃO MÍNIMA VERSUS EXPANSÃO PENAL}

social, em produto de outrem, o nome ou razão social deste, sem o seu consentimento; VII - atribui-se, como meio de propaganda, recompensa ou distinção que não obteve; VIII - vende ou expõe ou oferece à venda, em recipiente ou invólucro de outrem, produto adulterado ou falsificado, ou dele se utiliza para negociar com produto da mesma espécie, embora não adulterado ou falsificado, se o fato não constitui crime mais grave; IX - dá ou promete dinheiro ou outra utilidade a empregado de concorrente, para que o empregado, faltando ao dever do emprego, lhe proporcione vantagem; X - recebe dinheiro ou outra utilidade, ou aceita promessa de paga ou recompensa, para, faltando ao dever de empregado, proporcionar vantagem a concorrente do empregador; XI - divulga, explora ou utiliza-se, sem autorização, de conhecimentos, informações ou dados confidenciais, utilizáveis na indústria, comércio ou prestação de serviços, excluídos aqueles que sejam de conhecimento público ou que sejam evidentes para um técnico no assunto, a que teve acesso mediante relação contratual ou empregatícia, mesmo após o término do contrato; XII - divulga, explora ou utiliza-se, sem autorização, de conhecimentos ou informações a que se refere o inciso anterior, obtidos por meios ilícitos ou a que teve acesso mediante fraude; ou XIII - vende, expõe ou oferece à venda produto, declarando ser objeto de patente depositada, ou concedida, ou de desenho industrial registrado, que não o seja, ou menciona-o, em anúncio ou papel comercial, como depositado ou patenteado, ou registrado, sem o ser; XIV - divulga, explora ou utiliza-se, sem autorização, de resultados de testes ou outros dados não divulgados, cuja elaboração envolva esforço considerável e que tenham sido apresentados a entidades governamentais como condição para aprovar a comercialização de produtos. Pena - detenção, de 3 (três) meses a 1 (um) ano, ou multa. $\S 1^{\circ}$ Inclui-se nas hipóteses a que se referem os incisos XI e XII o empregador, sócio ou administrador da empresa, que incorrer nas tipificações estabelecidas nos mencionados dispositivos. $\S 2^{\circ} \mathrm{O}$ disposto no inciso XIV não se aplica quanto à divulgação por órgão governamental competente para autorizar a comercialização de produto, quando necessário para proteger o público (BRASIL, 1996). 
O Direito Penal deve atuar de forma mínima, isto é, apenas dever intervir na vida dos cidadãos nas situações em que a incidência de outros ramos do Direito não ofereça a necessária proteção, razão pela qual é considerado subsidiário e tido como ultima ratio (SANTOS, 2008, p. 6).

De acordo com o princípio da intervenção mínima, há duas principais formas ou meios que funcionam como indicativos da necessidade da atuação jurídico-normativa através do Direito Penal, os quais são desdobramentos da norma principal e assumem papel de subprincípios, quais sejam: $i$ ) princípio da fragmentariedade e; $i$ ) princípio da subsidiariedade (PRADO, 2010, p. 148).

O primeiro se refere ao fato de que a intervenção do Direito Penal somente se dará na esfera de direitos do indivíduo mediante relevante lesão ou perigo de lesão ao bem jurídico tutelado. O segundo se refere ao fato de que o Direito Penal só deve normatizar a proibição de determinadas condutas quando nenhuma das demais esferas do Direito for capaz de apresentar a devida proteção (AMARAL, 2013; MASSON, 2010, p. 51).

Tendo em vista tais princípios do Direito Penal, entende-se que a pena, precípua sanção criminal, somente deve ser utilizada pelo Estado quando este não dispuser de outros mecanismos para a solução pretendida (NUNES, 2011).

Com efeito, Bitencourt (1995, p. 32) expõe uma visão panorâmica a respeito do princípio sob estudo:

O princípio da intervenção mínima, também conhecido como ultima ratio, orienta e limita o poder incriminador do Estado, preconizando que a criminalização de uma conduta só se legitima se constituir meio necessário para a proteção de determinado bem jurídico. Se outras formas de sanções ou outros meios de controle social revelarem-se suficientes para a tutela desse bem, a sua criminalização será inadequada e desnecessária. Se para o restabelecimento da ordem jurídica forem suficientes medidas civis ou administrativas, são estas que devem ser empregadas e não as penais. Por isso, o direito penal deve ser a ultima ratio, isto é, deve atuar somente quando os demais ramos do direito revelarem-se incapazes de dar a tutela devida a bens relevantes na vida do indivíduo e da própria sociedade.

Por outro lado, tem-se, contemporaneamente, a contínua expansão penal, ou seja, o aumento da intervenção através do Direito Penal - seja através da criminalização de novas condutas, seja por intermédio do aumento das penas já previstas no 
ordenamento jurídico. Decerto, ao invés de figurar como ultima ratio, o Direito Penal tem, em muitos casos, assumido o papel principal (prima ratio) na busca pela proteção de determinados bens jurídicos que poderiam ser disciplinados de forma menos nociva (NUNES, 2011; PRADO, 2010, p. 116).

Diversas obras atuais buscam explicar o fenômeno da maximização penal por parte do Estado, como buscador da funcionalidade do Direito Penal, e as imbricações desse modelo - resultado da globalização neoliberal - com a observância dos direitos humanos fundamentais e o exercício de uma cidadania mínima (ANDRADE, 2016; NUCCI, 2016).

Um dos fatores da expansão penal, emergente da relação que circunda o Direito Penal e a observância da intervenção mínima, relaciona-se com o surgimento de novos bens jurídicos que necessitam de uma tutela criminal (NUNES, 2011).

Ocorre que o papel exacerbado do legislador tem acarretado um fenômeno que vem sendo denominado como "inflação de leis penais, ocasionando, por conseguinte, a crise de verificação do que é este ramo do Direito e para o que serve ou para o que deveria servir" (NUNES, 2011, p. 11). Andrade (2014, p. 92) complementa que:

[...] na prática, há uma verdadeira expansão do Direito Penal. Cada vez mais o legislador, movido pelo clamor popular e midiático, completamente alheio à técnica e aos princípios do Direito Penal, cria figuras incriminadoras, além de aumentar, sem qualquer justificativa prática ou racional, as penas dos crimes já existentes. A cada dia surgem mais crimes visando acalmar a opinião pública e combater de forma simbólica o crime, dando uma falsa sensação de segurança à população.

Nessa linha, percebe-se que a intervenção mínima objetiva manter a maior liberdade possível ao cidadão, somente incriminando condutas efetivamente intoleráveis ao convívio social.

Como apontado por Andrade (2014), a expansão do Direito Penal - entre outros fatores - tem sido principalmente associada ao clamor social por justiça e pela "fíctícia" preocupação do legislador em responder aos anseios sociais, visando não o bem coletivo, mas o falso atendimento das necessidades sociais.

A despeito da relação controvertida existente entre a expansão penal e o princípio basilar da intervenção mínima, tem-se que a ordem jurídico-penal está amparada nos ideais previstos constitucionalmente, a fim de garantir a determinados 
bens jurídicos previstos na $\mathrm{CF}$ a devida concretude, desde que observados os limites do Estado Democrático de Direito e a interpretação à luz da dignidade da pessoa humana (SARLET; WEINGARTNER NETO, 2016; BARROSO, 2016).

Aproximando ao tema central, assim como foi tratado no item anterior, o Direito de Propriedade Industrial - relacionado inclusive à defesa do consumidor ${ }^{5}$ - também reclama, na atualidade, a discussão sobre a relação entre a tutela de seus direitos e os bens jurídicos, por intermédio da intervenção penal (COSTA, 2005).

Nessa linha, não obstante a propriedade industrial ter sido tutelada na seara penal, de acordo com Villas (2011, p. 132),

os critérios de valoração dos bens de propriedade industrial feitos pelo legislador para a incriminação de suas violações colide com a importância de tais bens para o desenvolvimento social e econômico de uma nação, sendo reveladora da desproporcionalidade entre a gravidade das infrações, a propriedade industrial e a modicidade da intervenção estatal.

A esse respeito, importa refletir sobre até onde se deve considerar a expansão penal e o princípio da intervenção mínima diante das demandas apresentadas pela propriedade industrial ao âmbito penal, no pertinente à (in)efetividade dessa proteção.

\section{A (IN)EFETIVIDAdE DA PROTEÇÃo PENAL À PROPRIEDADE INDUSTRIAL}

Assentadas as considerações introdutórias, cabe apontar, partindo da reflexão proposta na seção anterior, problematizações relativas aos delitos dispostos na LPI.

Conforme Scudeler (2013), o esforço intelectivo exige gasto temporal, além daqueles relativos aos investimentos necessários para a formação intelectual, de modo que a atividade criativa raramente ocorre de forma causal, a prescindir do esforço humano para a consecução dos objetivos, seja mediante formulações de teorias, seja através das experiências.

\footnotetext{
${ }^{5}$ Art. 170. A ordem econômica, fundada na valorização do trabalho humano e na livre iniciativa, tem por fim assegurar a todos existência digna, conforme os ditames da justiça social, observados os seguintes princípios: [...] V - defesa do consumidor (BRASIL, 1988).
} 
Isso é demonstrado nas variadas dimensões insertas na proteção da propriedade intelectual, a exemplo da música - no âmbito dos direitos autorais -, e das marcas e patentes - no que diz respeito à propriedade industrial -, as quais projetam seus reflexos, sobretudo, no contexto empresarial, para além da "fundamental importância para o desenvolvimento tecnológico e econômico do país" (MELO e MALLMANN, 2015; TENÓRIO FILHO e MALLMANN, 2016; MALLMANN, 2016).

O progresso evolutivo dos seres humanos e o desenvolvimento da ciência somente foram factíveis a partir do trabalho criativo da espécie, proporcionando à sociedade e à ciência estruturas sólidas para a evolução. Como toda atividade laborativa, seja de cunho braçal ou intelectual, o exercício criativo também deve ser legalmente amparado e remunerado, sendo para tanto chamado a intervir o Direito, como ciência responsável por mediar e sanar os conflitos oriundos das relações sociais (SCUDELER, 2013).

Com o desenvolvimento da sociedade e o progresso industrial, novos conflitos são gerados. A globalização, assim como o surgimento das diversas tecnologias, forma processos altamente contributivos para os avanços científicos e tecnológicos da humanidade. No entanto, também promove conflitos e demandas ao mundo jurídico (MALLMANN, 2016).

De acordo com Villas (2011), de forma indesejável, paralelamente ao fenômeno da globalização, que possibilita a expansão dos mercados, do comércio internacional, da transferência de tecnologia e do incremento das finanças internacionais, além da transferência de rendas entre os países - o que é proveitoso para os países emergentes -, verifica-se também a globalização do crime, sendo a pirataria um de seus principais aspectos. É perceptível que esse fenômeno "marginal" subtrai os esforços lícitos envidados para a expansão saudável da economia mundial e para o seu consequente equilíbrio.

Desse modo, o Direito tende a sofrer alterações e inovações a fim de alcançar as novas demandas advindas das transformações sociais. No entanto, nem sempre essas alterações, de início, atendem fundamentalmente a todas as demandas geradas pela sociedade. 
A escolha do legislador infraconstitucional nas sanções penais às violações a bens industriais apresenta completa fragilidade e nenhuma veemência, quando analisados os preceitos secundários dos delitos, a exemplo daqueles previstos nos artigos 184, 188 e 190 da LPI. Tais preceitos preveem tão somente penas de 01 (um) mês a 03 (três) meses de detenção, ou multa (BRASIL, 1996). Desconsidera-se, então, de acordo com Villas (2011), que a pirataria é um fenômeno transnacional, que ocorre basicamente por meio do contrabando internacional.

A desproporção detectada nos tipos penais previstos nos artigos 184, 188 e 190 da LPI é bem mais visualizada quando comparada em seus preceitos secundários com a pena cominada na norma geral prevista para a conduta delituosa de exportar e importar mercadoria proibida, sob o prisma do princípio da especialidade (VILLAS, 2011). Assim, o crime de contrabando, previsto no art. 334 do Código Penal, tem como pena prevista a reclusão, de 2 (dois) a 5 (cinco) anos, aplicando-se em dobro caso o crime seja praticado em transporte aéreo, marítimo ou fluvial (BRASIL, 1940).

Em comparação aos trechos mencionados da LPI e do CP, é possível perceber a distorção entre as penalidades previstas, tornando-se os crimes contra a propriedade industrial algo pouco valorizado diante da refletida importância na sociedade.

Do mesmo modo, "a leveza verificada nas penas cominadas às infrações contra a propriedade industrial também conduz à enorme incidência de sentenças extintivas da punibilidade, em virtude da ocorrência da prescrição da pretensão punitiva estatal" (VILLAS, 2011, p. 152).

O citado autor conclui que:

Contudo, o maior obstáculo legal a uma profícua persecução penal aos crimes contra a propriedade industrial advém, sem sombras de dúvida, da maneira como se exerce o jus persequendi em juízo, em relação à repressão aos aludidos delitos, vez que, nesses delitos, procede-se somente mediante queixa, sendo a única exceção a do artigo 191 da Lei de Propriedade Industrial, que trata da reprodução ou imitação, de modo que possa induzir em erro ou confusão, de armas, brasões ou distintivos oficiais, nacionais, estrangeiros ou internacionais, sem autorização (VILLAS, 2011, p. 154).

Consequentemente, em decorrência de todos esses fatores, com a sensação de impunidade adquirida a partir da simplicidade das previsões de penas legais para os tipos penais explicitados na LPI, não há desestímulo à demanda, porquanto o 
consumidor que, de forma consciente, adere à aquisição de produtos piratas, não observa a repressão do Estado a tal prática, tendo, ao contrário, a sensação de permissividade na prática da pirataria e na falta de ofensa a esta atividade (VILLAS, 2011).

Em um segundo plano, com o aumento da demanda dos produtos piratas, as empresas violadas perdem mercado, ocasionando, assim, a diminuição da arrecadação tributária e a perda de empregos, num movimento constante e contínuo que afeta direta e indiretamente toda a sociedade, tornando um crime visto como de pequeno potencial ofensivo em uma grande ameaça aos interesses econômicos e sociais.

Para além da análise comparativa produzida pelos autores citados e acima descrita, ao analisar os delitos previstos entre os arts. 183 a 195 da LPI, observa-se que todos são crimes de menor potencial ofensivo, entendidos como aqueles que possuem pena máxima em abstrato igual ou inferior a 2 (dois) anos, cumulada ou não com multa (MASSON, 2010, p. 407).

A partir disso, verifica-se que a prática desses delitos se sujeita à disciplina e aos benefícios da Lei ${ }^{\circ}$ 9.099/1995 ${ }^{6}$, tais como a transação penal e a suspensão condicional do processo, sem falar na possibilidade de conversão de eventual pena privativa de liberdade em penas restritivas de direito, previsão esta trazida no CP (GRECO, 2012, p. 531).

Fillizola (2013), a partir de seus estudos sobre Direito Penal e propriedade intelectual, aponta que as legislações referentes aos crimes contra a propriedade industrial apresentam deficiências. Evidencia que é preciso corrigir, "aperfeiçoando-se a lei nos aspectos penais, e, principalmente, no que se refere aos aspectos processuais". Só então será possível o estabelecimento de um conjunto de normas capaz de oferecer "a necessária proteção aos titulares dos direitos de propriedade industrial e sancionar de maneira adequada os infratores" (FILIZZOLA, 2013).

De acordo com Villas (2011), as infrações contra a propriedade industrial deixam à mostra, portanto, a gravidade desses delitos e a objetividade jurídica que deveria ser protegida, uma vez que não se trata de tutela que diga respeito somente a interesses individuais, mas a interesses de toda a sociedade. Não apenas inventores,

\footnotetext{
${ }^{6}$ Lei no 9.099 , de 26 de setembro de 1995, que dispõe sobre os Juizados Especiais Cíveis e Criminais e dá outras providências (BRASIL, 1995).
} 
proprietários dos bens jurídicos, mas consumidores, tendem a ser gravemente lesionados nos crimes contra a propriedade industrial, cujas sanções são leves.

Ademais, após exaustiva persecução penal, é viável que a única pena que possa vir a ser aplicada seja a de multa, tendo em vista que sua cominação em relação aos delitos contra a propriedade industrial é alternativa (VILLAS, 2011). "De lege ferenda, a cominação da pena de multa em relação às infrações contra a propriedade industrial deveria, ao menos, ser cumulativa" (VILLAS, 2011, p. 154).

Somando-se todos os fatores descritos, tais como a distorção entre as penalidades previstas pela LPI e pelo CP para tipos penais equivalentes, percebe-se que a proteção dada pelo Direito Penal à propriedade industrial poderia ser mais efetiva, podendo ser considerada, em termos de avaliação teórica, como ineficaz, de modo que a impressão dos destinatários da norma é que, por se tratar de disciplina atinente ao Direito Civil, nele residiria a sua principal proteção, pertinente às possibilidades de reparação civil, a exemplo das indenizações, previstas na própria LPI.

\section{CONSIDERAÇÕES FINAIS}

A propriedade industrial, desdobramento da propriedade intelectual, é protegida nos âmbitos cível e criminal através da reparação civil, bem como pela criminalização de condutas consideradas prejudiciais aos regramentos pertinentes às marcas, patentes, indicações geográficas e concorrência desleal, conforme disciplinamento trazido na LPI, que regula os direitos e obrigações da referida área do Direito.

Não obstante haja proteção criminal, conforme se pretendeu demonstrar no presente trabalho, essa esfera jurídica deve ser sempre regida pela relação entre o princípio da intervenção mínima e a corrente da expansão penal, que visa - dentre as suas características - à funcionalidade do Direito Penal.

Assentada a necessidade de amparo jurídico-normativo à propriedade industrial, o legislador ordinário criminalizou determinadas condutas, as quais são previstas nos arts. 183 a 195 da LPI. Todavia, conforme demonstrado no decorrer deste trabalho, as penas para tais delitos foram previstas abstratamente em patamares bastante inferiores, se comparadas com aquelas previsões normativas do CP para delitos assemelhados. 
Para além, abordou-se questões processuais e desdobramentos legais afetos aos crimes de menor potencial ofensivo, tais como a incidência da transação penal, a suspensão condicional do processo, bem como a possibilidade de substituição por penas restritivas de direito.

Com efeito, entende-se, com amparo em estudos científicos anteriores, como deficientes as previsões penais, sobretudo no que diz respeito aos efeitos pedagógicos do Direito Penal, ao se considerar a "brandura com a qual o legislador infraconstitucional graduou as lesões aos bens jurídicos consubstanciados nos bens de propriedade industrial" (VILLAS, 2011, p. 131). Os impactos dessa deficiência repercutem não apenas para aqueles que têm lesionados seus direitos de propriedade, mas sobre todos, a exemplo dos consumidores, que deixam de ter asseguradas as origens dos produtos consumidos em seus cotidianos.

De forma mais abrangente, não é impreciso afirmar que toda a sociedade é atingida, mesmo que indiretamente, na medida em que menos impostos são gerados e refletidos em melhorias para a sociedade a partir das políticas por eles financiadas.

Não se pretende apontar para a expansão penal como uma solução, pois a criminalização em demasia não é adequada. Entretanto, no aspecto da imposição punitiva, entende-se pela necessidade de reformas legislativas, no sentido de conferir maior evidência aos efeitos pedagógicos. Nessa linha, embora os delitos previstos na LPI sejam elencados entre aqueles de menor potencial ofensivo, tem-se a evidência de que a proteção penal se destina à preservação dos bens jurídicos mais importantes de uma sociedade.

Desse modo, configurada a deficiência no próprio corpo legislativo, entendido como alicerce ou "estrutura básica da regulação de um ramo do Direito", "não há como olvidar que todos os esforços de proteção daí decorrentes são vãos” (VILLAS, 2011, p. 158-159).

\section{REFERÊNCIAS}

ANDRADE, André Lozano. Os problemas do direito penal simbólico em face dos princípios da intervenção mínima e da lesividade. In: Revista Liberdades: Instituto Brasileiro de Ciências Criminais (IBCCRIM), n. 17, set/dez 2014. Disponível em: <http://revistaliberdades.org.br/_upload/pdf/22/artigo06.pdf>. Acesso em: 18 abr. 2017. 
ANDRADE, Vera Regina Pereira de. Sistema penal máximo $x$ cidadania mínima: códigos da violência na era da globalização. 2.ed. Porto Alegre: Livraria do Advogado, 2016.

AMARAL, Junior Leite. O caráter fragmentário do direito penal e as limitações na atividade persecutória do Estado. In: Âmbito Jurídico: Rio Grande, XVI, n. 110, mar 2013. Disponível em: <http://www.ambito-

juridico.com.br/site/?n_link=revista_artigos_leitura\&artigo_id=13029>. Acesso em: 18 abr. 2017.

BARROSO, Luís Roberto. A dignidade da pessoa humana no direito constitucional contemporâneo: a construção de um conceito jurídico à luz da jurisprudência mundial. Belo Horizonte: Fórum, 2016.

BITENCOURT, Cezar Roberto. Lições de direito penal: parte geral. Porto Alegre: Livraria do Advogado, 1995.

BRASIL. Planalto. Constituição da República Federativa do Brasil de 1988. Disponível em:

<http://www.planalto.gov.br/ccivil_03/constituicao/constituicaocompilado.htm>. Acesso em: 18 abr. 2017.

BRASIL. Planalto. Decreto-Lei no 2.848, de 7 de dezembro de 1940: Código Penal. Disponível em: <http://www.planalto.gov.br/ccivil_03/decretolei/Del2848compilado.htm>. Acesso em: 18 abr. 2017.

BRASIL. Planalto. Lei $\mathbf{n}^{\circ}$ 9.099, de 26 de setembro de 1995: Dispõe sobre os Juizados Especiais Cíveis e Criminais e dá outras providências. Disponível em:

<http://www.planalto.gov.br/ccivil_03/leis/L9099.htm>. Acesso em: 18 abr. 2017.

BRASIL. Planalto. Lei no 9.279, de 14 de maio de 1996: Regula direitos e obrigações relativos à propriedade industrial. Disponível em:

<http://www.planalto.gov.br/ccivil_03/leis/L9279.htm>. Acesso em: 18 abr. 2017.

BRASIL. Tribunal Regional Federal - $3^{\text {a }}$ Região. Apelação criminal $\mathbf{n}^{\mathbf{0}}$

1999.61.81.003681-0. Quinta Turma, Relator: Desembargador Federal André

Nabarrete, 12 abril 2004. Disponível em:

<http://web.trf3.jus.br/acordaos/Acordao/BuscarDocumentoSita/63218142229050>.

Acesso em: 18 abr. 2017.

COELHO, Fábio Ulhoa. Manual de direito comercial: direito de empresa. 23.ed. São Paulo: Saraiva, 2011.

COSTA, Dahyana Siman Carvalho da. Propriedade industrial. In: Âmbito Jurídico, Rio Grande, VIII, n. 23, set 2005. Disponível em: 
$<$ http://www.ambito-juridico.com.br/site/index.php?n_link=revista_artigos_leitura\&arti go_id=246>. Acesso em: 18 abr. 2017.

FILIZZOLA, Ricardo Bandle. O processo penal e a proteção da propriedade industrial. Dissertação de Mestrado em Direito pela Pontifícia Universidade Católica de São Paulo - PUC/SP, 2005. Disponível em: <https://sapientia.pucsp.br/handle/handle/5790>. Acesso em: 18 abr. 2017.

FILIZZOLA, Ricardo Bandle. Direito penal e propriedade industrial. 2013. Disponível em: <http://filizzola.com.br/wp-content/uploads/2013/08/DIREITOPENAL-E-PROPRIEDADE-INDUSTRIAL.pdf >. Acesso em: 18 abr. 2017.

FRAGA, Vitor Galvão. Indicações geográficas no direito de propriedade industrial. In: Revista Jus Navigandi, Teresina, ano 18, n. 3790, 16 nov. 2013. Disponível em: <https://jus.com.br/artigos/25844>. Acesso em: 18 abr. 2017.

GRECO, Rogério. Curso de direito penal. 14.ed. Rio de Janeiro: Impetus, 2012.

HANNICKEL, Thomas. Confusão entre reprodução e imitação de marca é comum. In: Revista Consultor Jurídico (ConJur), 23 nov. 2013. Disponível em: $<$ http://www.conjur.com.br/2013-nov-23/thomas-hannickel-confusao-entre-reproducaoimitacao-marca-comum>. Acesso em: 18 abr. 2017.

MALLMANN, Querino. O valor \& o poder das marcas: tendências mercadológicas. In: Revista de Propriedade Intelectual - Direito Contemporâneo e Constituição (PIDCC), Aracaju, ano V, volume 10, n. 1, p. 90-99, fev/2016. Disponível em: <http://pidcc.com.br/artigos/102015/05022016.pdf>. Acesso em: 18 abr. 2017.

MASSON, Cleber. Direito penal: parte geral. Rio de Janeiro: Forense; São Paulo: Método, 2010.

MELO, Pedro José Costa; MALLMANN, Querino. A ação coletiva passiva para a tutela de patentes. In: Revista de Propriedade Intelectual - Direito Contemporâneo e Constituição (PIDCC), Aracaju, ano IV, volume 9, n. 2, p. 56-75, jun/2015. Disponível em: <http://pidcc.com.br/artigos/092015/01092015.pdf>. Acesso em: 18 abr. 2017.

NUCCI, Guilherme de Souza. Direitos humanos versus segurança pública. Rio de Janeiro: Forense, 2016.

NUNES, Joerberth Pinto. Expansão penal e intervenção mínima: paradoxos do direito penal contemporâneo. Dissertação de Mestrado em Direito pela Universidade do Vale do Rio dos Sinos - UNISINOS: São Leopoldo/RS, 2011. Disponível em: <http://www.repositorio.jesuita.org.br/bitstream/handle/UNISINOS/3163/Joerberth\%20 Pinto\%20Nunes.pdf>. Acesso em: 18 abr. 2017.

OLIVEIRA, Luis Henrique Rodrigues de. Crimes contra a patente de invenção e do modelo de utilidade na Lei de Propriedade Industrial. In: Revista Jus Navigandi, 
Teresina, ano 16, n. 2956, 5 ago. 2011. Disponível em: <https://jus.com.br/artigos/19705>. Acesso em: 18 abr. 2017.

PIERANGELI, José Henrique. Crimes contra a propriedade industrial e crimes de concorrência desleal. 1.ed. São Paulo: Editora Revista dos Tribunais, 2003.

PLETSCH, Laura Wolff. Desenho industrial: possibilidade de dupla proteção. Artigo extraído de Monografia de Graduação em Direito pela Pontifícia Universidade Católica do Rio Grande do Sul - PUC/RS, 2009. Disponível em:

<http://www3.pucrs.br/pucrs/files/uni/poa/direito/graduacao/tcc/tcc2/trabalhos2009_1/1 aura_pletsch.pdf >. Acesso em: 18 abr. 2017.

PRADO, Luiz Regis. Curso de direito penal brasileiro: parte geral - arts. $1^{\circ}$ a 120. vol.1. 9.ed. São Paulo: Revista dos Tribunais, 2010.

RAMOS, André Luiz Santa Cruz. Curso de direito empresarial: o novo regime jurídico-empresarial brasileiro. 4.ed. Salvador: JusPODIVM, 2010.

RODRIGUES, Maria Alice Castro; MENEZES, José Carlos Soares. A proteção legal à indicação geográfica no Brasil. In: Revista da ABPI, nº 48, set/out 2000. Disponível em:

$<$ http://www.abpi.org.br/biblioteca1a.asp?Ativo=True\&linguagem=Portugu\%EAs\&sec ao=Biblioteca\&subsecao=Revista\%20da\%20ABPI\&id=48>. Acesso em: 18 abr. 2017.

SANTOS, Juarez Cirino dos. Direito penal: parte geral. 3.ed. Curitiba: ICPC; Lumen Juris, 2008.

SARLET, Ingo Wolfgang; WEINGARTNER NETO, Jayme. Constituição e direito penal: temas atuais e polêmicos. Porto Alegre: Livraria do Advogado, 2016.

SCUDELER, Marcelo Augusto. A propriedade industrial e a necessidade de proteção da criação humana. In: Encontro Preparatório para o Congresso Nacional do CONPEDI, 2006, Recife. Florianópolis: Fundação Boiteux, 2006. Disponível em: $<$ http://www.publicadireito.com.br/conpedi/manaus/arquivos/anais/recife/politica_marc elo_scudeler.pdf>. Acesso em: 18 abr. 2017.

TENÓRIO FILHO, Geraldo Magela Freitas; MALLMANN, Querino. Direitos autorais musicais na sociedade da informação: usos alternativos e sua função social. In: V Encontro Internacional do CONPEDI Montevidéu - Uruguai (GT: Direito, inovação, propriedade intelectual e concorrência), 2016. Disponível em: <http://www.conpedi.org.br/publicacoes/9105o6b2/b081mk2i/FgT0mxw2DB7cza40.pd f>. Acesso em: 18 abr. 2017.

VILLAS, Marcelo Alberto Chaves. Desafios atuais no combate a infrações de propriedade industrial. In: Série Aperfeiçoamento de Magistrados, 2011. Disponível em: 
$<$ http://www.emerj.tjrj.jus.br/serieaperfeicoamentodemagistrados/paginas/series/3/Com bate_a_Pirataria_e_Agressao_131.pdf>.Acesso em: 18 abr. 2017. 